\title{
The Analysis of Different Factors Affecting the Red Wines Antioxidant Content
}

\author{
Anamaria D. HOSU' ${ }^{*}$, Claudia CIMPOIU ${ }^{1}$, Nastasia POP², Vasile \\ MICLAUȘ ${ }^{1}$, Sorana D. BOLBOACĂ $\check{3}^{3}$ Lorentz JÄNTSCHI ${ }^{4}$ \\ ${ }^{1}$ Babeş-Bolyai University, Faculty of Chemistry and Chemical Engineering, 11 Arany Janos, 400082 \\ Cluj-Napoca, Romania; hosuanamaria@yahoo.com (corresponding author) \\ ${ }^{2}$ University of Agricultural Sciences and Veterinary Medicine Cluj-Napoca, Faculty of Horticulture, 3-5 Mănăstur, 400372 Cluj-Napoca, Romania \\ 3 "Iuliu Hațieganu" University of Medicine and Pharmacy Cluj-Napoca, 13 E. Isac, 400023 Cluj-Napoca, Romania \\ ${ }^{4}$ Technical University of Cluj-Napoca, 103-105 Muncii Bvd., 400641 Cluj-Napoca, Romania
}

\begin{abstract}
The benefits of moderate consumption of wines consist in the protective effects against cardiovascular diseases and anticarcinogenic is associated with their antioxidants content. There are plenty of analytical methods for assessing the antioxidant content of wines but unfortunately, there is not a standardized method. The antioxidant content of 'Cabernet Sauvignon', 'Merlot' and 'Pinot Noir' wines obtained from cultivated grapes varieties from Recas and Minis Romanian vineyard from different harvesting years were investigated. The electron paramagnetic resonance spectroscopy, using the 2,2,6,6-tetramethyl-4-hydroxypiperidine-N-oxyl (Tempol) free stable radical, was used to determine the antioxidant content of wines. Measurements were done in order to analyze the effects of the grape varieties, the harvesting year and the vineyard on the antioxidant content of wines. The obtained results revealed that the antioxidant content of studied red wines depends on the harvesting year of grape, the grape variety and on the vineyard. Using the observed values of the antioxidant content, a relationship was identified between the antioxidant content of wines and the harvesting year of grapes. Furthermore, the designed generalized nonlinear model revealed that the antioxidant content of wine depends on the combined effect of the grape variety and the vineyard, besides the year, the grape variety and the vineyard.
\end{abstract}

Keywords: antioxidant content, electron paramagnetic resonance (EPR) spectroscopy, harvesting year, red wines, relationship, variety, vineyard

\section{Introduction}

The increased number of patients diagnosed with cancer, degenerative, cardiovascular and other diseases years has been correlated with inadequate nutrition (Ferguson, 2010; Gibson et al., 2010), stress (Guiraud et al., 2010; Cano and Iovanna, 2010) and exposure to various environmental factors (Mathers et al., 2010; Blonski et al., 2010). The mortality rate due to cardiovascular diseases proved to be smaller in populations with diets that include a moderate consumption of wine, when populations with similar risk factors (the consumption of unsaturated fats, the high cholesterol level, obesity, smoke, etc.) were compared (Teissedre, 2000). Moreover, the content of wine phenolics proved to have anticarcinogenic and protective effects against cardiovascular diseases. (Lamuela-Raventós and de la Torre-Boronat, 1999). The protective effects were explained by the high level of antioxidant compounds of wines "French Paradox" (Renaud et al., 1992), "Mediterranean diet" (Trichopoulou et al., 2003)).

Antioxidants belong to different chemical classes of compounds: flavonols, catechins, anthocyanins, etc.
(Dreosti, 2000, Vaya et al., 2001). The antioxidants have the main effect on the neutralization of the free radicals (Halliwell, 1995). The antioxidants analysis is necessary to determine their structures, their quantity, and/ or to investigate their ability to react with free radical (the antioxidant activity), in order to estimate their in vivo and in vitro effects. Two classes of methods are used for antioxidant analysis: chromatographic methods such as high performance liquid chromatography (Fang et al., 2007), and thin layer chromatography (Cserháti et al., 1998, Cimpoiu, 2006) and spectral methods such as spectrophotometry (UV-Vis) (Lachman et al., 2007), and electron paramagnetic resonance (EPR) spectroscopy (Staško et al., 2002)). Both classes of methods could be joined in different circumstances, depending on the objectives of the analysis. The second class of methods are generally used to measure the antioxidant content of pure compounds or of different samples of food (including wines) and body fluids based on their reaction with different free radicals. The frequently applied spectral method is UV-Vis spectrometry. 
160

The antioxidant content of wine samples proved to be influenced by the variety of grape (Tsanova-Savova et al., 2002), the climatic conditions (Pena-Neira et al., 2000), the material used for sample preparation (e.g. seeds, skin), the conditions under samples are obtained (FernandezPachon et al., 2004; Halpern, 2008, Hosu et al., 2010) and so on.

The aim of the research was to investigate the influence of three factors (grape variety, year of harvest and vineyard) on the antioxidant content of wines.

\section{Materials and methods}

\section{Materials}

Wines from three different varieties of Vitis vinifera sp.: 'Cabernet Sauvignon'-commercial name 'Cabernet Sauvignon' (abbreviated as CS), 'Pinot Noir'-commercial name 'Burgund' (abbreviated as PN) and 'Merlot'-commercial name 'Merlot' (abbreviated as TM), obtained from different harvest years from Recas (I) and Minis (II) vineyard (Romania) (Tab. 1) were studied in terms of their antioxidant capacity. Samples of wine, purchased from the market, were analyzed directly, without any preparation step.

The solution of 2,2,6,6-tetramethyl-4-hydroxypiperidine-N-oxyl (Tempol) (Fluka, Germany) free radicals $(0.01 \%)$ was prepared in methanol (Chimopar, Bucharest, Romania). The number of free radical molecules decreases in time, with different rates, depending on the concentration of antioxidants, when the samples of wine containing antioxidant compounds react with Tempol molecules.

Tab. 1 . The analyzed wines

\begin{tabular}{cccc}
\hline $\begin{array}{c}\text { Commercial } \\
\text { name }\end{array}$ & Vineyard & Year & $\begin{array}{c}\text { Alcohol } \\
\text { content }(\% \mathrm{~V})\end{array}$ \\
\hline CS & I & 2002 & 13.5 \\
CS & I & 2003 & 13.5 \\
CS & I & 2005 & 13.0 \\
CS & II & 1995 & 12.5 \\
CS & II & 2000 & 13.5 \\
TM & I & 2003 & 13.5 \\
TM & I & 2005 & 13.0 \\
PN & I & 2005 & 12.5 \\
\hline
\end{tabular}

$\mathrm{CS}=$ 'Cabernet Sauvignon,' TM= 'Merlot', PN= 'Burgund'

Vineyards: I=Recas, II=Minis

\section{EPR measurement of antioxidant activity}

Five samples of $20 \mu \mathrm{l}$ of red wine were injected using a Hamilton microsyringe into a quartz capillary $(10 \mathrm{~cm}$ length and interior diameter $1 \mathrm{~mm}$ ) and $5 \mu \mathrm{l}$ of methanolic solution of Tempol were rapidly added. Samples were monitored using an EPR Spectrometer (ADANI portable EPR Spectrometer PS8400, Resonance Instruments Instruments Inc., Germany), operating in X-band $(9.1 \mathrm{GHz} \div 9.6 \mathrm{GHz})$ equipped with a computer acquisi- tion system. The spectrometer parameters were: modulation frequency $100 \mathrm{KHz}$, sweep width $100 \mathrm{G}$, sweep time 30 s, receiver gain $2 \times 10^{1}$. The EPR spectra were recorded from 2 to 2 minutes, for 20 minutes. The antioxidant capacity of extracts was characterized by the decrease in time of the relative concentration of the paramagnetic species obtained by double integration of EPR signals (Petrişor $e t$ al., 2008).

\section{Determination and analysis of antioxidant content}

The values obtained by double integration of the initial EPR signal of the free radicals $\left(S_{0}\right)$, and the values determined after 20 minutes following adding the extracts of wines $\left(S_{20}\right)$ were used in order to determine the antioxidant content (Hosu et al., 2011). The following formula was used:

Antioxidant content $(\%)=\left[\left(\mathrm{S}_{0}-\mathrm{S}_{20}\right) / \mathrm{S}_{0}\right] \cdot 100$

The normal distribution of the experimental data was tested by EasyFit (v.5.2) and Statistica (v.8.0) software. The following statistical tests were used in assessment of experimental data normality: Kolmogorov-Smirnov (K-S) (Kolmogorov, 1941; Smirnov, 1948), Wilk-Shapiro (W-S) (Shapiro, 1968), Anderson-Darling (A-D) (Anderson and Darling, 1952) and Jarque-Bera (J-B) (Jarque and Bera, 1980; Jarque and Bera, 1981). The analysis of variances was conducted using Statistica (v.8.0) software. The summary of antioxidant content was expressed as mean, associated 95\% confidence interval, standard deviation, and coefficient of variation. The $95 \%$ confidence intervals associated with proportions were calculated as described by Fieller (1940). The Chi-Square test (Fisher, 1923) was applied to test the independence between pairs of factors (variety and harvesting year) that are able to influence the antioxidant content of the studied wines.

\section{Results and discussion}

The antioxidant content (expressed as \%) calculated for each sample is presented in Tab. 2.

The results of normality analysis of experimental data are presented in Tab. 3.

Tab. 2. The antioxidant content of studied wines

\begin{tabular}{cccccc}
\hline \multirow{2}{*}{ AC\% } & \multicolumn{5}{c}{ Samples } \\
\cline { 2 - 6 } & 1 & 2 & 3 & 4 & 5 \\
\hline CSI 2002 & 49.87 & 50.04 & 50.21 & 49.98 & 49.91 \\
CSI 2003 & 27.91 & 28.02 & 27.99 & 28.00 & 27.97 \\
CSI 2005 & 18.85 & 18.79 & 18.83 & 18.98 & 18.87 \\
CSII 1995 & 69.98 & 69.98 & 69.96 & 70.03 & 70.12 \\
\hline CSII 2000 & 69.49 & 69.53 & 69.51 & 69.6 & 69.56 \\
TMI 2003 & 56.45 & 56.72 & 56.64 & 56.38 & 56.62 \\
\hline TMI 2005 & 35.68 & 35.93 & 35.79 & 35.92 & 35.7 \\
PNI 2005 & 28.13 & 28.42 & 28.40 & 29.09 & 28.42 \\
\hline
\end{tabular}

$\mathrm{AC} \%=$ Antioxidant content $(\%)$

$\mathrm{CS}=$ 'Cabernet Sauvignon', $\mathrm{TM}=$ 'Merlot', PN = 'Burgund' 
Tab. 3. The analysis of normality of antioxidant content

\begin{tabular}{lcccccccc}
\hline Wine & K-S & $\mathrm{p}_{\mathrm{K}-\mathrm{S}}$ & W-S & $\mathrm{p}_{\mathrm{W}-\mathrm{S}}$ & $\mathrm{A}-\mathrm{D}$ & $\mathrm{p}_{\mathrm{A}-\mathrm{D}}$ & $\mathrm{J}-\mathrm{B}$ & $\mathrm{p}_{\mathrm{J}-\mathrm{B}}$ \\
\hline CSI 2002 & 0.188 & 0.980 & 0.932 & 0.609 & 0.253 & 0.733 & 1.088 & 0.581 \\
CSI 2003 & 0.225 & 0.914 & 0.912 & 0.479 & 0.312 & 0.683 & 2.095 & 0.351 \\
CSI 2005 & 0.266 & 0.790 & 0.909 & 0.464 & 0.330 & 0.669 & 2.461 & 0.292 \\
CSII 1995 & 0.301 & 0.662 & 0.839 & 0.161 & 0.466 & 0.570 & 2.524 & 0.283 \\
CSII 2000 & 0.173 & 0.992 & 0.970 & 0.875 & 0.179 & 0.800 & 0.353 & 0.838 \\
TMI 2003 & 0.259 & 0.815 & 0.923 & 0.548 & 0.287 & 0.704 & 0.971 & 0.615 \\
TMI 2005 & 0.237 & 0.882 & 0.863 & 0.238 & 0.362 & 0.644 & 1.807 & 0.405 \\
PNI 2005 & 0.380 & 0.366 & 0.814 & 0.106 & 0.592 & 0.491 & 4.160 & 0.125 \\
\hline CS= 'Cabernet Sauvignon', TM= 'Merlot', PN= 'Burgund' \\
pX=probability from the test X, where X: K-S=Kolmogorov-Smirnov, \\
W-S=Wilk-Shapiro, A-D=Anderson-Darling, J-B=Jarque-Bera
\end{tabular}

The results presented in Tab. 3 showed that the normal distribution of all observed data cannot be rejected at $5 \%$ significance level. Additional, for only three of cases a greater departure from normality could be observed ranging from $10 \%$ to $20 \%\left(\mathrm{p}_{\mathrm{W}-\mathrm{S}}\right.$ and $\mathrm{p}_{\mathrm{J}-\mathrm{B}}$ for PNI 2005; $\mathrm{p}_{\mathrm{W}-\mathrm{S}}$ for CSII 1995). All other cases proved to be in a greater agreement with the theoretical normal distribution. Therefore, the statistical analysis under proved normal distribution was further conducted, since the results showed that the calculated probability of all statistical tests and all observables considered, was higher than 0.05 . The results of analysis of the variance conducted in order to estimate the values of the antioxidant content of wines are presented in Tab. 4 .

Tab. 4. Antioxidant content: descriptive statistics

\begin{tabular}{ccccc}
\hline Wine & Mean & StD & CV\% & CI95\% \\
\hline CSI 2002 & 50.00 & 0.13 & 0.27 & $50.00 \pm 0.17$ \\
CSI 2003 & 27.98 & 0.04 & 0.15 & $27.98 \pm 0.05$ \\
CSI 2005 & 18.86 & 0.07 & 0.38 & $18.86 \pm 0.09$ \\
CSII 1995 & 70.01 & 0.06 & 0.09 & $70.01 \pm 0.08$ \\
CSII 2000 & 69.54 & 0.04 & 0.06 & $69.54 \pm 0.05$ \\
TMI 2003 & 56.56 & 0.14 & 0.25 & $56.56 \pm 0.18$ \\
TMI 2005 & 35.80 & 0.12 & 0.33 & $35.80 \pm 0.15$ \\
PNI 2005 & 28.49 & 0.36 & 1.25 & $28.49 \pm 0.44$ \\
\hline
\end{tabular}

Wine: grape variety, vineyard and harvesting year; Mean = arithmetic mean; $\mathrm{StD}=$ Standard deviation; $\mathrm{CV} \%=$ coefficient of variation; $\mathrm{CI} 95 \%=$ half of the confidence interval width of mean

Tab. 5. Antioxidant content ratios between wines (relative to the highest value)

\begin{tabular}{ccc}
\hline Wine & Value & Proportion \\
\hline CSII 1995 & $70.01 \pm 0.08$ & $1.000 \pm 0.001$ \\
CSII 2000 & $69.54 \pm 0.05$ & $0.993 \pm 0.001$ \\
TMI 2003 & $56.56 \pm 0.18$ & $0.808 \pm 0.002$ \\
CSI 2002 & $50.00 \pm 0.17$ & $0.714 \pm 0.002$ \\
TMI 2005 & $35.80 \pm 0.15$ & $0.511 \pm 0.001$ \\
PNI 2005 & $28.49 \pm 0.44$ & $0.407 \pm 0.005$ \\
CSI 2003 & $27.98 \pm 0.05$ & $0.400 \pm 0.001$ \\
CSI 2005 & $18.86 \pm 0.09$ & $0.269 \pm 0.001$ \\
\hline
\end{tabular}

Wine: grape variety, vineyard and harvesting year; Value: result from Tab. 4 Proportion (from highest) and associated 95\%CI
Tab. 4 provided along with the mean value of the antioxidant content, its confidence interval calculated at a 5\% significance level (Value column in Tab. 4). The coefficients of variation (CV \%) proved to be less than $1 \%$ for most of the wine samples; these values showed a low variability of the observations from repeated measurements, and in the same time indicate a good agreement between them.

The analysis from Tab. 4 revealed the following statements:

$\div$ The antioxidant content of wines vary from $18.86 \pm 0.09$ (for CSI 2005) to $70.01 \pm 0.08$ (for CSII 1995 ) all of them being statistically different by each other (Tab. 5);

$\div$ The $95 \%$ confidence intervals of PNI 2005 and CSI 2003 are near to be overlapped; when ratio between them are calculated (Tab. 5), the confidence of the ratio for $95 \%$ confidence vary from 1.005 to 1.032; thus the statistically significant difference between them are assured at 5\% significance level (both limits are greater than 1). It should be noted that same result can be obtaining by applying student $\mathrm{t}$-test to compare two means.

Tab. 5 presented the relative antioxidant content of wines reported to the highest value (CSII 1995). As Tab. 5 revealed, all antioxidant contents significantly varied (at a significance level of 5\%) among the samples analyzed. The ratio of antioxidant content varied from 1 (when are compared the CSII 1995 to itself) to 0.269 (for CSI 2005). In view of that, the range of antioxidant content of the investigated wines varied significantly (the lowest antioxidant content is less than one third of the highest content).

An assumption can be verified for the data presented in Tab. 4: if there is (or not) a relationship between the observed mean (of antioxidants content) and the year (of harvesting) and variety (of cultivated grapes). The results of the Chi-Square test for the four entries presented in Tab. 4 (CSI 2003, CSI 2005, TMI 2003, and TMI 2005) are presented in Tab. 6 .

The analysis of results presented in Tab. 6 clearly indicates that there is a relationship between antioxidant content and year and variety. By using the same data presented in Tab. 4 a relationship between the year of harvesting $\left(y_{h}\right.$ in Eq.1) and the antioxidant content (AC(\%) in Eq.1) was identified:

$$
\begin{aligned}
& \mathrm{AC}(\%)=9490( \pm 6654)-4.72( \pm 3.32) \cdot \mathrm{y}_{\mathrm{h}} \\
& \mathrm{n}=8 ; \mathrm{r}=0.82 ; \mathrm{r}_{\text {adj }}^{2}=0.61 ; \mathrm{SE}=12.26 ; \mathrm{F}_{(1)}=12 ; \mathrm{p}_{\mathrm{F}}=
\end{aligned}
$$
$1.3 \%$;

$$
\mathrm{t}(9490)=3.49 ; \mathrm{p}_{\mathrm{t}}(3.49)=1.3 \% ; \mathrm{t}(4.72)=3.47 ;
$$
$\mathrm{p}_{\mathrm{t}}(3.47)=1.3 \%$;

The hypothesis verified in Tab. 6 that there is no reason to reject the hypothesis that the wine antioxidant content is a observable dependent on the harvesting year is further confirmed by the statistical analysis resulted and presented in eq. (1). Eq. 1 provides an estimation of the true relationship between the populations of all wine sorts harvested in different years (did not take into account the sort-variety or vineyard, but estimates the average of them). Fig. 1 presents the relationship given in Eq. (1). 
162

Tab. 6. Is the antioxidant content dependent by year and variety? Results

\begin{tabular}{|c|c|c|c|}
\hline $\begin{array}{c}\text { Variety } \backslash \\
\text { Year }\end{array}$ & 2003 & 2005 & \\
\hline CSI & $27.98(28.45)$ & $18.86(18.39)$ & \\
\hline TMI & $56.56(56.09)$ & $35.8(36.27)$ & $\mathrm{X}^{2}=0.029 ; \mathrm{p}(0.029,1) \approx 0.86$ \\
\hline
\end{tabular}

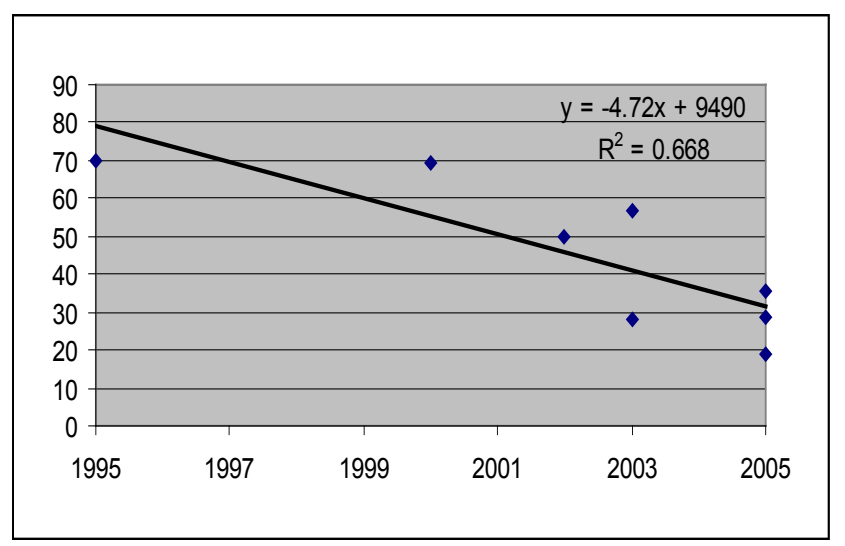

Fig. 1. Antioxidant contents of wines depending on harvesting year
Over $61 \%$ of the variance in the data could be explained by the linear relationship (1) between antioxidant content and harvesting year. A general view of wines population reveals the evolution in time of their antioxidant content; the population constituted from the three wines from 2005 year and the three characteristic points corresponding to the antioxidant content of different variety of wines could represent an estimator of mean antioxidant content of wines population from that year. Consequently, using the identified equation, the maturation time needed to reach a given antioxidant content could be probably estimated.

A generalized nonlinear model (GLZ) was designed in order to deeply explain the variance of antioxidant content using year (continuous variable), variety and vineyard (categorical variables) as predictors: $\hat{Y}=\sum a_{i} X_{i}+\sum b_{i} X_{i} X_{i}$. Only first 7 entries from Tab. 4 were included into the analysis (the last entry in the table provides no information regarding the association, being the only one containing PN variety). Four significant components were identified in the model: year, variety, vineyard, and combined effect of variety and vineyard (Tab. 7).

The statistical analysis presented in Tab. 7 revealed that all effects are statistically significant (with p values less than

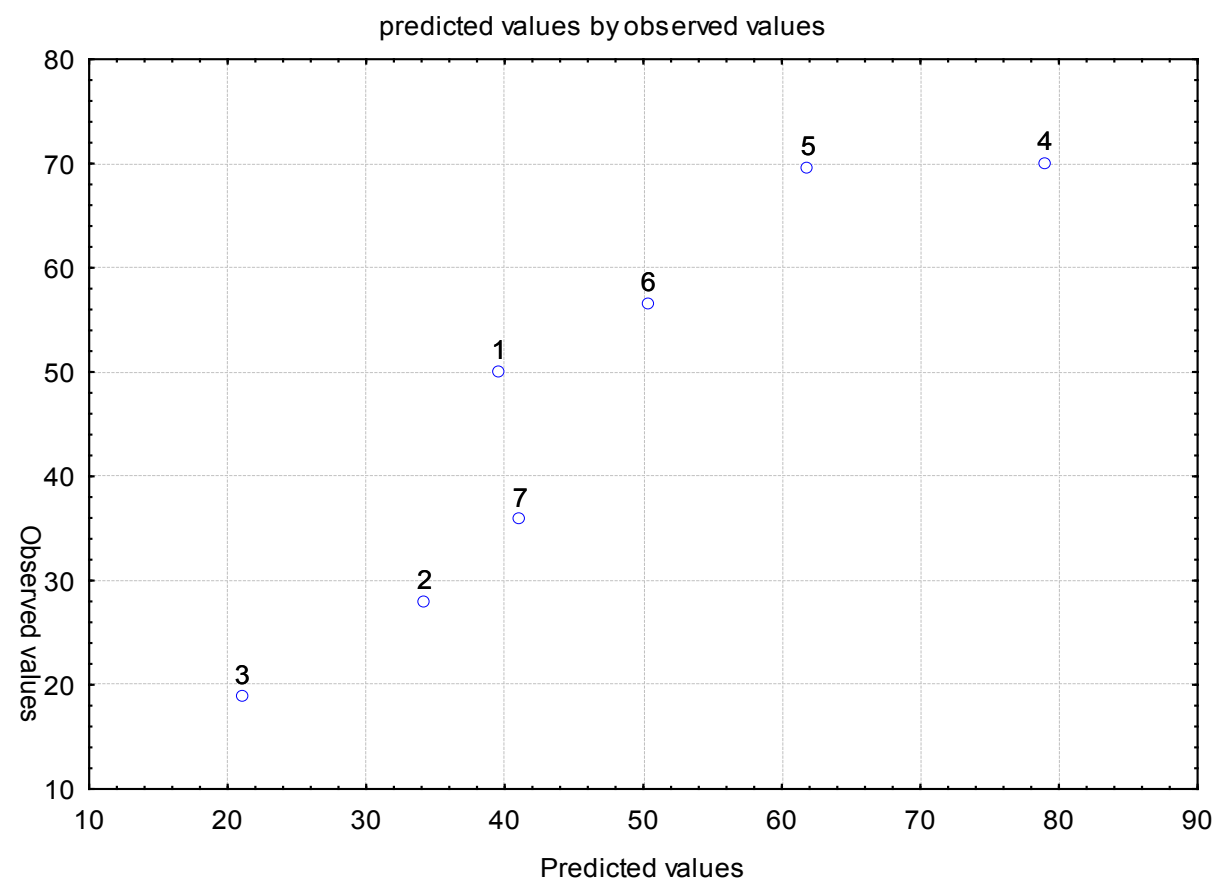

Fig. 2. GLZ estimated vs. observed antioxidant content $\left(n=7 ; r=0.92 ; r^{2}{ }_{\text {adj }}=0.77\right)$

Tab. 7. Analysis with GLZ Model (assumptions: NORMAL Distribution, POWER Link function)

\begin{tabular}{ccccccc}
\hline Effects & Column & Estimate & $95 \%$ CI & SE & Wald* & $p$ \\
\hline "Var3" & year & -114 & {$[-196 ;-32]$} & 42 & 7.4922 & $0.006197^{* *}$ \\
"Var1" & variety & 228942 & {$[65603 ; 392280]$} & 83337 & 7.5469 & $0.006011^{* *}$ \\
"Var2" & vineyard & 228948 & {$[65356 ; 392540]$} & 83467 & 7.5239 & $0.006088^{* *}$ \\
"Var1"*"Var2" & - & -229130 & {$[-392482 ;-65779]$} & 83344 & 7.5582 & $0.005974^{* *}$ \\
Scale & & 7 & & 1.91 & 14.000 & $0.000183^{* *}$ \\
\hline
\end{tabular}

${ }^{*}$ Wald statistic; ${ }^{* *}$ Statistically significant to the model 
1\%). Using the model, a good agreement was obtained between observed antioxidant content and estimated antioxidant content (Fig. 2).

The obtained GLZ model, through considering the categorical variables, was to improve the observed determination of the relationship relating antioxidant content and the production year (about $77 \%$ of the total variance are explained by the GLZ, and only $61 \%$ by the eq. 1 ) as the analysis with chi square test suggested (that antioxidants depends on both year and variety)

\section{Conclusions}

The presented study was conducted on the wines from three varieties of red grapes ('Cabernet Sauvignon', 'Pinot Noir' and 'Merlot'), produced in different years and obtained from different vineyards. The antioxidant content was assessed in terms of harvesting year of grape, the grape variety and vineyard. The obtained results revealed that the antioxidant content of studied red wines depends on the harvesting year of grape, the grape variety and on the vineyard. Using the observed values of the antioxidant content, a relationship was identified between the antioxidant content of wines and the harvesting year of grapes. Furthermore, the designed generalized nonlinear model revealed that the antioxidant content of wine depends on the combined effect of variety and vineyard, besides the year, the variety and the vineyard.

\section{Acknowledgments}

This research was supported by CNCSIS-UEFISCSU, project number PNII-RU 203/2010.

\section{References}

Anderson TW, Darling DA (1952). Asymptotic theory of certain "goodness-of-fit" criteria based on stochastic processes. Ann Math Stat 23(2):193-212.

Blonski W, Kotlyar DS, Forde KA (2010). Non-viral causes of hepatocellular carcinoma. World J Gastroenterol 16(29):3603-3615.

Cano CE, Iovanna JL (2010). Stress proteins and pancreatic cancer metastasis. Scientific World Journal 10:1958-66.

Cimpoiu C (2006). Analysis of some natural antioxidants by thin-layer chromatography and high performance thin-layer chromatography. J Liq Chromatogr Rel Tech 29:11251142.

Cserháti T, Forgées E, Kosa Á, Csiktusnadi-Kiss G, Candais M (1998). Use of multistep gradient elution TLC to gradient separation in HPLC. J Planar Chromatog Mod TLC 11(1):34-37.

Dreosti IE (2000). Antioxidant polyphenols in tea, cocoa, and wine. Nutrition 16:692-694.

Fang F, Li MJ, Pan QH, Huang DW (2007). Determination of red wines flavonoids by HPLC and effect of aging. Food Chem 101:428-433.

Ferguson LR (2010). Dietary influences on mutagenesis--where is this field going? Environ Mol Mutagen 51(8-9):909-18.

Fernandez-Pachon MS, Villano D, Garcia-Parrilla MC, Troncoso AM (2004). Antioxidant activity of wines and relation with their polyphenolic composition. Anal Chim Acta 513:113-118.

Fieller EC (1940). The biological standardization of insulin. J Roy Stat Soc 7(1):1-64.

Fisher RA (1923). Studies in crop variation. II. The manurial response of different potato varieties. J Agric Sci 13:311320.

Gibson TM, Ferrucci LM, Tangrea JA, Schatzkin A (2010). Epidemiological and clinical studies of nutrition. Semin Oncol 37(3):282-96.

Guiraud V, Amor MB, Mas JL, Touzé E (2010). Triggers of ischemic stroke: a systematic review. Stroke 41(11):26692677.

Halliwell B (1995). Antioxidant characterization. Biochem Pharmacol 49:1341-1348.

Halpern GM (2008). A celebration of wine: wine is medicine. Inflammopharmacology 16:240-244.

Hosu A, Cimpoiu C, Miclăuş V, Damian G, Tarsiche I, Pop N (2010). Influence of intermittent heating during maceration on the antioxidant capacity of some grape seeds and skins. Not Bot Hort Agrobot Cluj 38(1):41-43.

Hosu A, Cimpoiu C, Miclăuş V, Jantschi L (2011). Antioxidant content of three different varieties of wine grapes. Biotech Biotechnol Equip 25:2217-2221.

Jarque CM, Bera AK (1980). Efficient tests for normality, homoscedasticity and serial independence of regression residuals. Econ Lett 6(3):255-259.

Jarque CM, Bera AK (1981). Efficient tests for normality, homoscedasticity and serial independence of regression residuals: Monte Carlo evidence. Econ Lett 7(4):313-318.

Kolmogorov A (1941). Confidence Limits for an Unknown Distribution Function. Ann Math Stat 12(4):461-463.

Lachman J, Sulc M, Schillla M (2007). Comparison of the total antioxidant status of Bohemian wines during the winemaking process. Food Chem 103:802-807.

Lamuela-Raventós RM, de la Torre-Boronat MC (1999). Beneficial effects of white wines. Drugs Exp Clin Res 25(23):121-124.

Mathers JC, Strathdee G, Relton CL (2010). Induction of epigenetic alterations by dietary and other environmental factors. Adv Genet 71:3-39.

Pena-Neira A, Hernández T, García-Vallejo C, Estrella I, Suarez JA (2000). A survey of phenolic compounds in Spanish wines of different geographical origin. Eur Food Res Technol 210:445-448

Petrişor D, Damian G, Simon S, Hosu A, Miclăuş V (2008). 
164

Antioxidant activity, of some types of white wines and juices investigated by EPR spectroscopy. Mod Phys Lett B 22:26892698.

Renaud S, de Lorgeril M (1992). Wine, alcohol, plateles, and the French paradox for coronary heart disease. Lancet 339:1523-1526.

Shapiro SS, Wilk MB, Chen HJ (1968). A comparative study of various tests of normality. J Am Stat Assoc 63:1343-1372.

Smirnov NV (1948). Table for estimating the goodness of fit of empirical distributions. Ann Math Stat 19(2):279-281.

Staško A, Liptáková M, Malík F, Mišík V (2002). Free radical scavenging activities of white and red wines: An EPR spin trapping study. Appl Magn Reson 22:101-113.
Teissedre PL, Landrault N (2000). Wine phenolics: contribution to dietary intake and bioavailability. Food Res Int 33:461467.

Trichopoulou A, Costacou T, Bamia C, Trichopoulou D (2003). Adherence to a Mediterranean diet and survival in a Greek population. N Engl J Med 348:2599-2608.

Tsanova-Savova S, Ribarova F (2002). Free and conjugated myricetin, quercetin, and kaempferol in Bulgarian red wines. J Food Compos Anal 15:639-645.

Vaya J, Aviram M (2001). Nutritional antioxidants: mechanism of action, analyses of activities and medicinal applications. Curr Med Chem: Immunol, Endocr Metab Agents 1:99117. 